\title{
How to use a mask
}

\section{Mengzhu Fu}

\begin{abstract}
In the beginnings of the COVID-19 pandemic, Asians wearing masks in white colonized countries became a target of white supremacist violence. This piece of fabric has been a point of contention for anti-maskers who feel like their freedoms are being threatened. To dispel the myths of why people might wear masks, this is a basic IOI tutorial on how to use a mask. The comic tutorial breaks down what this apparently exotic cultural artifact is, why people wear it and how to use it properly. This is directed at white people so that next time they see East Asians wearing face masks, they will be equipped with all the relevant information to NOT punch us in the face, kick us out of supermarkets, bully Asian hospital workers, or abuse us on the streets or online. This comic was inspired by the safety instruction cards on flights and the patronizing posters in Anglo-colonial university washrooms that tell Chinese students not to stand on the toilet seats. Thanks to Kirsty Fong for the idea and for being a reference.
\end{abstract}

\section{Keywords}

COVID-19, masks, racism, pandemic symbolism, white supremacy 


\section{HOW TO USE A MASK}
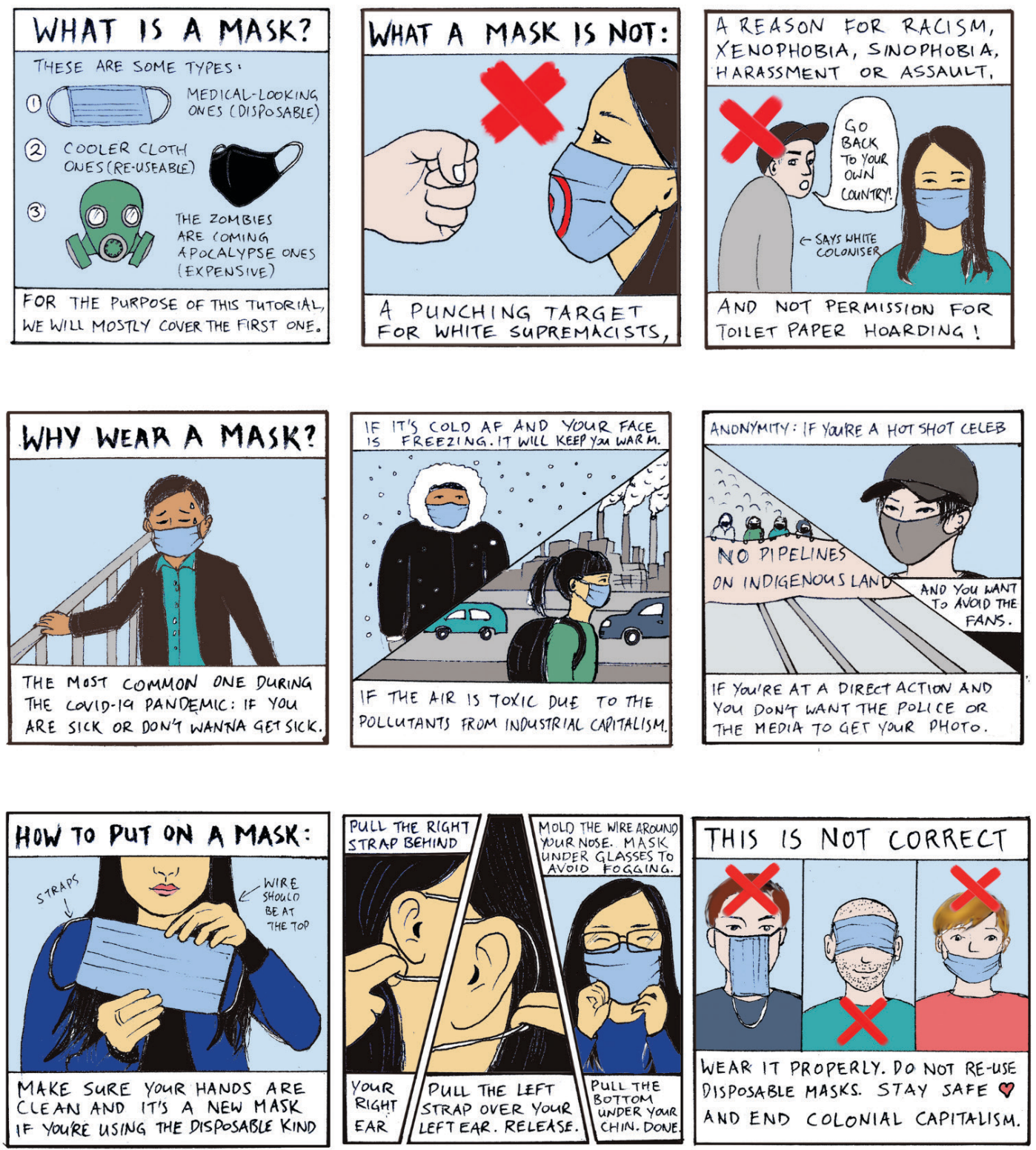

FB: @FUFIGHTERARTS

INSTA: @FUFIGHTERARTS 


\section{Author biographies}

Mengzhu Fu is a PhD student in the Gender, Feminist and Women's Studies Department at York University. As a grandchild of farmers, factory workers, and educators, they have been involved in grassroots activisms aimed at racism, gender-based violence, and migrant solidarity for Indigenous sovereignty, most of which was in Aotearoa (New Zealand). Their MA research focused on the lifeworlds of young Asian survivors of domestic violence in Aotearoa (New Zealand) through an analysis of structural violence, age, and intersectionality. They enjoy zine-making, using traditional art media, tattooing, and creating comics. Self-published zines that they were involved in creating include issues 2-9 of Mellow Yellow, an Asian feminist zine that was started by Wai Ho in circa. 2005, and a recent zine called Intersectional Youth Leadership, which is based on a decade of youth work in Asian, African, and Middle Eastern immigrant communities in Aotearoa. Currently, they are a co-editor of the blog, Te Tangi a Te Ruru (the Cry of the Ruru), which features voices of Indigenous writers and people of colour who are signalling warnings in a time of colonial capitalism and calling for otherworlds to be birthed. 